\title{
Revista Brasileira de Enfermagem REBEn \\ Percepção dos profissionais de saúde sobre a comunicação com os familiares de pacientes em UTIs
}

Kátia Massuda Alves Batista dos Santos

Mestre em Enfermagem. Enfermeira de Educação Continuada do Hospital e Maternidade São Cristóvão. kmassuda@usp.br

Maria Júlia Paes da Silva

Professora Titular do Departamento de Enfermagem Medico-Cirúrgica da Escola de Enfermagem da Universidade de São Paulo. juliaps@usp.br

Dados parciais da dissertação de mestrado: Santos KMAB. Percepção dos profissionais de saúde sobre a comunicação com os familiares de pacientes em sobre a comunicação com os familiares de pacientes em
UTIs e análise proxêmica dessas interações [dissertação]. São Paulo (SP): Escola de Enfermagem, Universidade de São Paulo; 2004.

\author{
Perception of helthcare professionals about communication with \\ relatives of ICU patients
}

Percepción de los profesionales de salud con respecto a la comunicación con los familiares de pacientes en UTIS

PESQUISA

\section{RESUMO}

A pesquisa objetivou verificar como os profissionais de saúde percebem a comunicação com os familiares de pacientes internados em UTI. A coleta de dados foi realizada em um hospital privado e envolveu 37 profissionais de saúde, sendo obtida por meio de entrevistas semi-estruturadas, gravadas em fita cassete. A análise de conteúdo demonstrou duas grandes categorias: aspectos que dificultam a comunicação com os familiares e aspectos que facilitam a comunicação com os familiares. Os aspectos que dificultam a interação sobressaíramse em relação aos que facilitam: informações nem sempre compreendidas pelos familiares, a gravidade do paciente, a dinâmica da unidade, o grau de desconhecimento pelo profissional da evolução clínica do paciente, dificuldades no jeito de ser do profissional e o espaço físico inadequado.

Descritores: Comunicação; Relações profissional-família; Cuidados intensivos.

\section{ABSTRACT}

This study aimed at verifying how health professionals proceed the communication with the patient's relatives at the ICU. Data collection was carried out in a private hospital with 37 health professionals and was obtained by means of semi-structured interviews. Analysis of the content showed two major categories: aspects that make communication difficult with the family and the aspects that make communication easier with the family. Aspects that make the interaction difficult were more significant in relation to the others: information was not always well understood by the family, patient's severity, dynamics of the unit, professional's lack of knowledge about the patient's clinical evolution, some difficulties regarding the way of the professional to be and the inadequate physical space.

Descriptors: Communication; Professional-family realtions; Intensive care.

\section{RESUMEN}

Este estudio tuvo como objectivo verificar como los profisionales de la salud perciben la comunicacción con los familiares de pacientes internados en la UTI. La recolecta de datos fue realizada en un hospital particular y envolvió 37 profesionales de salud. La recolecta fue hecha a través de entrevistas semi-estructuradas. El análisis del contenido demostró dos grandes categorías: aspectos que dificultan la comunicación con los familiares y aspectos que facilitan la comunicación con los familiares. Los aspectos que dificultan la interacción se sobresalen en relación a los que facilitan; informaciones no siempre comprendidas por los familiares, la gravedad del paciente, la dinámica de la unidad, el grado de desconocimiento por el profisional de la evolución clínica del paciente, dificultades en la manera de ser del profisional y el espacio físico inadecuado

Descriptores: Comunicación; Relaciones proefesional-familia; Cuidados intensivos.

Santos KMAB, Silva MJP. Percepção dos profissionais de saúde sobre a comunicação com familiares de pacientes de UTIs. Rev Bras Enferm 2006 jan-fev; 59(1): 61-6.

\section{INTRODUÇÃO}

A comunicação é um processo dinâmico envolvendo um intercâmbio de mensagens enviadas e recebidas que influenciam no comportamento das pessoas a curto, médio ou longo prazo(1). Sua finalidade é possibilitar ao profissional de saúde e ao paciente delinearem as necessidades a serem atendidas, para ajudar a pessoa que está sendo cuidada sentir-se um ser humano digno e com autonomia para solucionar seus problemas, visando a promoção, manutenção e recuperação de sua saúde física e mental, como também encontrar novos padrões de comportamento diante de uma situação inesperada ${ }^{(1,2)}$.

Embora a comunicação efetiva seja fundamental para o exercício da prática profissional, podemos observar em muitos estudos ${ }^{(3-8)}$, a existência de aspectos que interferem negativamente na interação entre profissionais de saúde e familiares. A sobrecarga de trabalho ou a falta de tempo $0^{(3,5,6,8), \text { a }}$ supremacia dada a rotina de trabalho em relação a interação com o familiar ${ }^{(4,6,8)}$, a falta de 
treinamento ${ }^{(5)}$, a exclusão da família no processo de cuidar do paciente ${ }^{(4,5,7,8)}$, constituem os aspectos negativos relacionados. Outro aspecto estudado que interfere negativamente na interação entre profissional e família, são as situações com alta demanda emocional, como a piora das condições clínicas do paciente ${ }^{(3,5,8)}$. Os enfermeiros sentiram-se ineficazes e com dificuldade para oferecer assistência à família. Como conseqüência, os profissionais tentaram proteger-se a si mesmos por meio do distanciamento, evitando um envolvimento pessoal com a família; alguns até observaram que se tornaram duros e sem compaixão(8).

Por outro lado, os aspectos que interferem positivamente na interação entre profissional e família foram relacionados com o interesse do profissional em conhecer o familiar como uma pessoa, e seu desejo em estabelecer essa relação, a espontaneidade em mostrar seus sentimentos ou falar sobre algumas informações pessoais, ouvir e responder as questões da família ${ }^{(3,4,8)}$. A empatia dos enfermeiros pelo familiar também colaborou de forma positiva para a interação entre profissionais de saúde e familiares ${ }^{(5,8)}$.

A habilidade dos enfermeiros em interagir com os familiares foi aprendida com o passar do tempo, pelas suas experiências pessoais e profissionais; quando estabelecidas com sucesso, otimizam o tempo de trabalho do enfermeiro e influem positivamente também nos cuidados com o paciente ${ }^{(8)}$. Foi observado que os profissionais de saúde não comentaram sobre a necessidade de discutir as estratégias adotadas pela família para enfrentar a hospitalização de um familiar ${ }^{(3,8)}$. Porém, a insegurança dos enfermeiros foi óbvia durante a comunicação com os familiares, ao conversar sobre as dificuldades emocionais dos membros da família ${ }^{(8)}$. Por intermédio desses estudos observa-se que há aspectos que interferem negativamente e outros positivamente no estabelecimento das interações.A saúde física e emocional dos membros da família é afetada quando um deles sofre alteração em seu bem estar ${ }^{(9)}$. Diante disso, percebemos que estamos frente a um ser que não precisa necessariamente de condutas terapêuticas, mas com certeza, de cuidado. Um cuidado que requer a articulação da compaixão, consciência, competência e confiança ${ }^{(9,10)}$.

\section{OBJETIVO}

- Verificar como os profissionais de saúde percebem a comunicação com os familiares de pacientes internados em UTI.

\section{METODOLOGIA}

3.1 Tipo de estudo: trata-se de um estudo exploratório descritivo e de campo.

3.2 Local do estudo: foi realizado em uma Unidade de Terapia Intensiva UTI) da Clínica Médico Cirúrgica de um hospital privado de porte médio, da cidade São Paulo. Nesta unidade existem 12 leitos e uma equipe multiprofissional composta de enfermeiros, auxiliares de enfermagem, técnicos de enfermagem, fisioterapeutas, médicos intensivistas e nutricionistas. As nutricionistas não surgem na análise dos dados porque, no momento das visitas hospitalares na UTI, não foi observada nenhuma interação entre elas e familiares.

3.3 População: constituiu-se de 37 profissionais de saúde que atuaram com familiares de pacientes internados na UTI.

3.4 Procedimentos de coleta dos dados: previamente, foi obtida a autorização do Comitê de Ética e Pesquisa da Instituição participante do estudo. Os participantes do estudo foram informados quanto ao objetivo do trabalho, e aqueles que concordaram participar assinaram o Termo de Consentimento Livre e Esclarecido, conforme a resolução
CNS 196/96, sendo-lhes garantido o anonimato das respostas. Foi aplicado um questionário para verificar o perfil dos profissionais de saúde e, a seguir, foram realizadas entrevistas, gravadas em fita cassete, com a questão norteadora: como é para você comunicar-se com a família de um paciente internado na UTI? As entrevistas foram encerradas quando não surgiram mais conteúdos novos a respeito do fenômeno investigado. 0 período de coleta dos dados ocorreu entre 10 de março e 9 de abril de 2004.

3.5 Tratamento dos dados: Para as entrevistas, o referencial usado para a análise de conteúdo foi o proposto por Bardin ${ }^{(11)}$, que sugere as seguintes etapas para análise do material: pré-análise, exploração do material e tratamento dos resultados. A análise de conteúdo é um recurso que analisa a comunicação para além de seus significados imediatos e utiliza procedimentos sistemáticos e objetivos de descrição do conteúdo das mensagens.

\section{RESULTADOS}

Aceitaram participar do estudo 37 profissionais de saúde, sendo dez enfermeiros, nove médicos, quinze técnicos de enfermagem, dois fisioterapeutas e um psicólogo. Os profissionais apresentaram idade média de 32 anos, variando entre 21 e 52 anos. Em relação a variável sexo, verificou-se predomínio do sexo feminino $25(67,5 \%)$ sobre o sexo masculino $12(32,4 \%)$. Os enfermeiros, sem exceção, eram do sexo feminino. 0 tempo médio de formado foi de oito anos, variando entre menos de um mês e vinte anos, e o tempo médio de experiência do profissional foi de sete anos, variando entre quatro meses e vinte e um anos e meio. O tempo de experiência foi maior que o tempo de formado, porque alguns profissionais já atuavam em UTI, embora exercendo outra função na área da saúde.

A partir das falas foi possivel perceber duas grandes categorias que descrevem a percepção dos profissionais quanto a comunicação com os familiares: categoria 1- Aspectos que dificultam a comunicação com os familiares $(n=57)$ e, categoria 2-Aspectos que facilitam a comunicação com os familiares $(n=36)$.

\section{Categoria 1- Aspectos que dificultam a comunicação com os} familiares

A categoria 1 prevaleceu em relação à categoria 2. Resultado nada surpreendente, considerando-se a complexidade do processo de comunicação somada aos problemas inerentes ao ambiente UTI.

Na subcategoria 1 - Informações incompreendidas $(n=22)$, as falas indicam que as mensagens verbais emitidas pelos profissionais de saúde nem sempre são compreendidas pelos familiares. Por outro lado, a dificuldade da família compreender as mensagens acaba refletindo nos sentimentos e comportamentos dos profissionais no momento do diálogo com o familiar no horário da visita hospitalar. Nas falas, surge a reflexão sobre a própria comunicação entre os membros da equipe da saúde, que também repercute na compreensão e consistência das informações dadas aos familiares. O fato da família poder interpretar mal as informações, faz com que os técnicos e auxiliares de Enfermagem forneçam um menor número de informações possíveis, ou até mesmo, fiquem calados e solicitem a presença dos enfermeiros para atender os familiares.

"Às vezes, eu me calo e falo: aguarde um pouco que a enfermeira vem conversar, só isso". (E25)

Sentir que a comunicação com a família de pacientes internados em uma UTI é difícil, às vezes até cansativa, também foi um aspecto manifesto pelos profissionais de saúde diante de informações incompreendidas.

"Eu acho que é a parte mais cansativa da UTI, conversar com o 
familiar. Às vezes, até pela dificuldade de até falar uma coisa e aí saber que a família não vai entender, não entende". (E17)

As falas também demonstram que, especificamente os profissionais de Enfermagem de nível médio, sentem que a família não valoriza suas informações.

"[...] muitas vezes, a nossa comunicação com a família fica difícil, por que a própria família não quer conversar com os técnicos, para ela é mais importante conversar com o médico". (E15)

Exclusivamente nas falas dos profissionais de nível médio revelouse um certo grau maior de dificuldade para fornecer informações aos familiares, comentando até que a família interrogaria menos sobre 0 estado geral dos paciente se houvesse maior abertura para todos os profissionais da Enfermagem conversar com ela.

"Sabe, às vezes, você fica naquela angústia, peito doendo, você não pode chegar e conversar. A gente fala 'ah! o enfermeiro vai falar com o senhor', e você doida para falar 'fez isso, abriu o olho, ele mexeu a perna', mas a gente não tem esse acesso. Eu acho que se a Enfermagem fosse mais aberta para conversar com a família, seria diferente, não interrogariam tanto, sairiam daqui com uma expectativa maior, mas, infelizmente, não é assim". (E14)

Percebemos nas falas que a incompreensão das informações fornecidas pelos profissionais de saúde aos familiares, pode estar relacionada também com o baixo nível socioeconômico e cultural, o uso de termos técnicos, o fato do profissional sentir que assistir o paciente é prioridade e a falta de coerência nas informações fornecidas.

A perda de informações entre um plantão e outro é outra possivel causa da incompreensão das informações; particularmente o plantão noturno, dificulta aos profissionais de Enfermagem responderem ou atenderem algumas questões dos familiares, e assim, acabam fornecendo uma resposta com certa incoerência apenas para evitar dúvidas.

"Não que a gente não saiba, mas muitas informações se perdem. Às vezes, perguntam, a gente fica com uma cara de interrogação de certas coisas que a gente não sabe responder[...] e temos que ter um jogo de cintura para poder contornar aquela situação e dar uma resposta um pouco coerente, para não ficar um vazio". (E32)

Na subcategoria 2 - A gravidade do paciente $(n=10)$, as falas destacam a intensidade do desafio dos profissionais ao abordarem a família quando as condições clínicas de seu familiar internado é grave.

"A parte mais difícil é quando você tem que contar para a família que o paciente não está evoluindo de acordo como a gente gostaria... aí que a nossa intervenção é mais importante, no sentido de acalmar a familia, de deixá-los mais tranqüilos quanto aos procedimentos, de dizer realmente o que estamos fazendo". (E1)

Neste discurso é possível perceber que a dificuldade em comunicarse com a família é a de informar que tudo o que foi feito com o paciente não obteve resultados satisfatórios, ou seja, o paciente não está evoluindo conforme as expectativas da equipe da saúde. Observamos que não foram citadas intervenções que ofereçam um suporte emocional aos familiares ou que respondam outras dúvidas, não necessariamente sobre os procedimentos que o paciente está sendo submetido.

"Eu nunca parei para pensar por que eu fico constrangida, mas eu acredito que é por isso. Às vezes, a pessoa acredita na vida daquela pessoa e você, que têm mais experiência e está lá dentro, sabe que aquela pessoa não vai sair; então, você tem que dar uma esperança falsa para o familiar". (E3)

Notamos que o profissional não havia refletido sobre as causas de seu constrangimento diante da necessidade de dar uma notícia ao familiar sobre a gravidade do paciente. Acredita que, talvez, seja por saber que o paciente já está muito próximo de sua finitude, porém sente que a família crê "na vida daquela pessoa", acaba dando-lhe uma falsa esperança. Em outra fala, apesar de referir sobre a necessidade de fornecer informações claras e fidedignas aos familiares, hesita em "abrir tudo" (falar toda a verdade à família) diante de um paciente grave. Assim, falsa esperança e informações incompletas podem ser dadas à família que tenha um paciente em estado grave na UTI.

"Eu acho complicado, principalmente quando o paciente é grave, de explicar, até onde posso falar (para os familiares), se eu devo abrir tudo mesmo". (E35)

A seguir, observamos que o profissional de saúde diante de um paciente grave, tende a falar mais tecnicamente e de forma mais geral, com os familiares, para evitar seus questionamentos.

"Por que o paciente que está na UTI é um paciente mais grave, né? Então é difícil. Essa paciente que está aí agora mesmo. Foi muito difícil para mim. Eu até procurei falar mais tecnicamente (com o familiar) para não ficar explicando muitos detalhes, para não entrar muito no porquê, porque tem muito disso, paciente está com "dobuta"(medicação), mas eu procuro, assim, falar de uma forma mais geral, mas eu acho difíil". (E11)

A próxima fala torna explícito como a gravidade do paciente reflete no modo como os profissionais de saúde comunicam-se com a família. Observamos que a complexidade do estado geral de um paciente, na fala de um profissional de saúde, torna a comunicação com o familiar mais complicada.

"[...] Quando o paciente é mais instável, já fica mais complicada a comunicação. Você tem que usar um tom de voz como se fosse respeito. Então, você não consegue brincar tanto é mais formal do que informal". (E27).

Fica claro ainda que a maneira de comunicar-se com a família muda conforme o estado do paciente e do familiar, sendo formal, alterando até o tom de voz quando, clinicamente, o paciente é grave; e informal, havendo até brincadeiras, quando as condições clínicas do paciente são estáveis ou, até mesmo, tendo muito cuidado com o que é falado aos familiares que estão agressivos para não ter reclamações posteriores.

Na subcategoria 3 - Dinâmica da unidade $(n=9)$, as falas dos profissionais relatam suas dificuldades em contatar com a família, quando há atividades que são ou devem ser realizadas no horário da visita. $A$ dinâmica da unidade retratada na falta de tempo, falta de pessoal, intercorrências e telefonemas, são aspectos encontrados nas falas que dificultam a comunicação com os familiares.

"O número de funcionários, às vezes, é pouco para estar atendendo todo mundo, tem uma enfermeira só. Às vezes, a gente vai falar para aliviar um pouco e, quando chega em um assunto que a gente não consegue e nem pode falar, dai a gente chama a enfermeira". (E5)

"Infelizmente, a gente fica muito presa ao telefone. E é impressionante, geralmente é bem nos horários da visita". (E7) 
Na fala a seguir, notamos que a interação entre profissional e família fica prejudicada, pois o profissional até "foge" da família em razão da dinâmica atribulada da unidade, porque não pode "perder tempo" com os familiares.

"Muitas coisas, tempo, não é todo dia que eu tenho tempo de perder 15 minutos com uma família; só que, quando eu sei que eu não vou ter tempo para conversar, eu nem entro para conversar, eu até fujo da familia um pouco". (E9)

Na subcategoria 4 - Grau de conhecimento do paciente e familiar $(n=7)$, as falas revelam que o grau de conhecimento do paciente e familiar influencia na comunicação com o familiar.

Quando não existe esse conhecimento, percebe-se uma necessidade premente desses profissionais em conhecerem previamente as condições clínicas do paciente, para que informações precisas possam ser dadas para os familiares e amenizar sua sensação de desconforto (sentimento que é difícil, que incomoda). Observável, também, é a decisão do profissional não conversar ou conversar superficialmente com a família, desviar o assunto ou sentir que fica "estampado" em sua face quando não sabe de forma precisa o que está falando, por que não houve tempo hábil de conhecer previamente os dados clínicos dos pacientes internados na UTI, preferindo até mesmo estar com o paciente a ficar com a família.

O conhecimento insuficiente da evolução clínica do paciente está relacionado com a falta de comunicação adequada entre os componentes da equipe, na passagem de plantão e, o horário de visita que dificulta ao profissional, que está iniciando o seu turno de trabalho, avaliar previamente 0 doente antes do contato com a família e, portanto, fornecer adequadamente as informações.

"Quando você não sabe responder uma coisa, você começa a desviar para outro assunto, para fugir daquilo. Isso me incomoda, por que eu sou extremamente exata nas minhas coisas, então se eu não sei, fica na minha cara quando eu não sei aquilo que estou falando.[...] Então, é assim, durante todo o trabalho na UTI eu prefiro mil vezes mais estar com o paciente do que com a família". (E37)

O acompanhamento fragmentado das condutas terapêuticas de um indivíduo hospitalizado, expresso por alguns médicos, interfere em saber com exatidão todos os dados da evolução do paciente e o grau de conhecimento da família sobre o diagnóstico e prognóstico do familiar internado. As fases emocionais da família durante a hospitalização do paciente, aceitação, negação, raiva e barganha, foram aspectos observados em uma das falas. Ter noção da fase em que a família se encontra provavelmente facilitaria a comunicação entre o profissional e familiar.

"Um dos problemas é da falta de continuidade, é não saber, primeiro porque o paciente não é seu, e segundo porque você não sabe o que a família sabe. Porque tem médico que se esconde, tem médico que fala demais. Médico teve uma reclamação (a família reclamou que o médico referiu que seu familiar estava grave) porque a família achou que o colega falou que o paciente estava grave e não poderia ter falado e, realmente, estava. Então, quer dizer, você vai pegar várias fases, de aceitação, de negação, de raiva e barganha. Você não sabe qual fase está a família, mas você se expõe pra caramba. Isso é um grande problema". (E37)

Nas falas observamos também que conhecer o paciente foi mais preponderante, e que conhecer a família não envolve saber suas estratégias de sobrevivência para se adaptar ao processo de hospitali- zação de um familiar. Evidencia-se a centralização do cuidar no paciente.

"Às vezes, não é nem o tempo da visita, eu não tive tempo antes de ver como o paciente está, de ver o que ele teve de evolução para estar passando alguma coisa real para ele. Aí, também, eu vou tentar não conversar ou conversar superficialmente". (E9)

"À noite é pior, termina de pegar o plantão e a família já entra. Se é um paciente novo, às vezes, mesmo que você pegue o plantão, você sabe muito pouco, você não sabe direito". (E11)

Na subcategoria 5 - Dificuldades no jeito de ser do profissional $(n=5)$, as falas retratam a influência da percepção que um profissional possui sobre si mesmo, à maneira como se expressa com a família.

$\mathrm{Na}$ fala a seguir, o jeito de ser, mau humorado, ríspido e pouco prestativo, muitas vezes, pode implicar não ficar tão próximo à família ou esperar que esta tenha iniciativa de abordar 0 outro.

"Assim, às vezes, eu não fico tão perto, porque eu tenho um jeito de ter uma cara mais fechada, dá impressão que sou uma pessoa que não dou atenção. Então, o parente pensa, né? Essa mulher é tão mau humorada, mas não, é o meu jeito (...) É o meu jeito mesmo, quando eu me aproximo, eu procuro fazer o melhor para disfarçar um pouco essa carranca que eu tenho, mas é só a carranca que eu tenho mesmo, o coração é grandão". (E22)

O jeito de ser, compreendido neste estudo como personalidade e expresso nas falas, demonstra como os profissionais percebem a si mesmo e em relação aos familiares.

Na subcategoria 6 - 0 espaço físico inadequado $(n=4)$, as falas descrevem aspectos negativos durante o contato com a família, no momento da visita hospitalar, quando esse espaço é inadequado.

A falta de um local para conversar com os familiares fica explícita em algumas falas, sendo citado, inclusive, que no momento em que 0 médico está conversando com os familiares, existem até pessoas da manutenção transitando. As condições precárias de hotelaria causam até um sentimento de desconfiança no familiar sobre a qualidade do atendimento, quando a pessoa internada possui um convênio melhor ou conceituado no mercado.

"Quando vem pessoas com convênio de grupos melhores ou níveis melhores, o conceito que as pessoas tem de hotelaria, fica uma situação de desconfiança e, as vezes, fica um pouco mais difícil". (E36)

"Você vai dar uma notícia importante, mas um entra e desvia completamente a atenção, e a família fica olhando para outras coisas, para o Rx do outro doente que está sendo visto". (E18)

Esta última fala retrata fidedignamente o cotidiano de um espaço utilizado no momento da visita, com muitas interferências auditivas e visuais, pessoas transitando com ou sem objetos e falando.

\section{Categoria 2 - Aspectos que facilitam a comunicação com os} familiares

A categoria 2 indica uma mobilização para a cuidado humano, pois demonstra interesse em adentrar o espaço de vida do familiar, aproximando-se da família. Evidencia um movimento para humanizar a UTI, porque demonstra o profissional esforçando-se para perceber a experiência do outro, praticando a comunicação empática, tendo paciência, sendo prestativo e procurando compreender o sofrimento da família.

Na subcategoria 1 - Aproximar-se da família $(n=19)$, percebemos 
que a aproximação entre o familiar e o profissional ocorre basicamente de dois modos: o profissional aproxima-se da família ou espera ser abordado pelo familiar. Observamos que $20(54 \%)$ dos profissionais têm a iniciativa de achegar-se à família, e 17(45,9\%) esperam que a família tenha iniciativa de aproximar-se de algum profissional. Pelas falas, é possivel perceber também que o profissional fica atento à expressão facial do familiar, sendo o olhar um dos meios que sinaliza o momento que pode ocorrer a aproximação entre eles.

A aproximação entre médico e familiares, psicólogo e familiares, obrigatoriamente acontece porque existe um horário determinado pela instituição ou um horário previamente acordado entre as partes interessadas.

Quando, nas falas, os profissionais aguardam a aproximação da família, demonstram prontidão para responder às suas dúvidas. Algumas referem que esperam a abordagem da família porque o tempo de visita é insuficiente para que ela esteja com o paciente. Por outro lado, uma fala alerta sobre a necessidade do profissional de saúde saber a hora de se aproximar da família, para não interferir indevidamente no momento em que está havendo interação importante entre familiar e paciente.

"Logo que eles chegam no paciente, fico perto. Muitos têm o momento deles, rezam. Você tem que saber a hora que você deve chegar". (E2).

Observamos também, pelas falas, que os profissionais de nível médio aproximam-se literalmente da família, realizando procedimentos de Enfermagem, como verificando os equipamentos, conversando superficialmente sobre o estado geral do paciente, a fim de surgir "novos assuntos", falando sobre Deus com os familiares que demonstram tristeza.

"Eu me aproximo do leito, eu verifico os equipamentos, pergunto para o paciente se está tudo bem, muitas vezes, a gente chega na família e verifico se dá para trazer um hidratante, um desodorante, alguma coisa, assim, explico por que, né? É assim que eu vou chegando neles para ver como eles reagem". (E15)

Outras falas revelam que existem momentos em que esses mesmos profissionais aproximam-se do familiar porque percebem essa necessidade no modo de olhar da família ou porque "sentem" sua tristeza e, não estão, necessariamente, associados com a realização de procedimentos.

"Às vezes, eu sinto que a família está deprimida, ai eu chego lá, falo para acreditar em Deus [...]" (E25)

O olhar do familiar é um sinal importante para indicar seu desejo de ser abordado por alguém, caso não ocorra aproxima-se até o local onde pode obter as devidas informações.

"É tudo no olhar. Eles ficam olhando a gente. Eles ficam procurando ou até perguntam para alguém quem vai dar informação. Muitos chegam até o balcão". (E9)

A sensação de que fica mais fácil quando há um conhecimento mútuo entre profissionais e familiares, após as sucessivas aproximações, também foi descrita nas falas.

"[...] na UTI, com pacientes mais crônicos, a maioria das famílias eu já conheço; mesmo não gostando de falar com as famílias, já tenho uma relação boa, ele já sabe do jeito que eu falo, fica mais fácil, do que se eu tivesse que conhecer todos os doentes e famílias de uma vez só”. (E18)

Na subcategoria 2 - Empatia $(n=7)$, as falas dos profissionais de saúde revelam que a semelhança de experiências de vida entre eles e familiares ajuda a compreender e aproximar-se mais da família.

A empatia é vista como facilitadora à convivência com a família, permitindo falar com o outro da melhor forma possivel, responder às perguntas dos familiares, entender seu sofrimento, ter paciência e entender que a família pode interpretar a comunicação não-verbal do profissional conforme sua percepção, podendo julgá-lo como maleducado, ignorante e "estúpido".

"Tem que ter paciência, ver o lado deles, né? Como o paciente que está no leito, né? Tem que entender eles um pouco, porque de repente pode ser a minha família que esteja na mesma situação, então, tem que saber lidar com aquela família [...]" (E24)

Dessa forma, quando nas falas a comunicação é empática, podemos dizer que há uma mobilização dos profissionais para a humanização da UTI.

Na subcategoria 3 - Experiência profissional $(n=5)$, as falas também deixam claro que a experiência profissional facilita a comunicação porque favorece a percepção das reações dos familiares (defensiva, agitação, preocupação) mediante o que é falado, ajuda discernir o que é importante para diminuir a ansiedade do familiar, beneficia o conhecimento e visão do quadro geral do paciente.

"Então, para passar para alguém, você fica meio receoso, tipo "ah! o que vão me perguntar? O que eles vão querer saber?" $E$ se eu não souber responder... Acho que até gera um pouco de ansiedade no início, mas conforme você vai tendo um pouquinho mais de experiência, vai se acostumando e, como disse antes, conhecendo o quadro, e tendo uma visão legal do paciente, tranqüilo. Isso vai sendo eliminado com o tempo". (E10)

"Os anos da profissão ajudam a discernir melhor que isso (a comunicação) é importante para diminuir a ansiedade da família, do paciente e ajudar na recuperação". (E13)

Na subcategoria 4 - Idade avançada do familiar $(n=3)$, as falas demonstram que a idade é uma característica da pessoa que pode determinar o tipo de aproximação. Há evidências nos discursos de que o idoso, só pela sua idade, estimula a aproximação do profissional.

"[...] nos mais idosos, vou direto; é necessário que a gente vá até eles. Eles não vão chamar, às vezes chamam, mas ficam assustados.

É como se fosse uma criança também, que vê aquilo tudo diferente. Agora quando são mais novos, eles chamam". (E5)

Percebemos que existe uma crença, um valor estimulando o profissional à aproximar-se do idoso. Crença que favorece o acolhimento, embora colabore com o estigma do idoso ser uma pessoa que retorna à infância, sendo dependente.

$\mathrm{Na}$ categoria 5 - Autoconhecimento $(n=2)$, as falas constatam a importância do autoconhecimento para entender e assistir melhor o outro, humanizando a assistência à saúde. Em uma das falas, a mudança de valores, após uma reflexão que provocou maior autoconhecimento, colaborou para uma melhor aceitação do limite da saúde, permitindo ao profissional até discutir sobre a viabilidade do tratamento terapêutico; facilitou a comunicação do profissional com o familiar, uma vez que a relação ficou mais tranqüila e mais próxima.

"Eu já consigo trabalhar melhor isso; quando o paciente é sem 
prognóstico...agora já consigo trabalhar melhor isso, inclusive com a familia; de estar orientando, falando o que é melhor, o que é pior para o paciente. Que não é a gente quem julga, claro, não é a gente quem decide, é o paciente e o moço lá em cima...É assim, já foi mais difícil, agora está mais tranqüilo para mim neste sentido. Até por que estou conseguindo aceitar mais a limitação da saúde". (E9)

0 resultado dessa pesquisa valoriza a fala a seguir, em que foi possivel observar que a reflexão de suas atitudes pode levar a distinguir quais eram realmente seus valores e quais eram os do outro, permitindo uma maior proximidade com o outro.

"[...] E eu preciso fazer uma separação, uma distinção, para poder estar, pelo menos, compreendendo o que é meu, o que é do outro, né? O que são questões minhas e o que é do outro, para a gente poder estar trabalhando isso de uma forma cada vez mais próxima é... de evolução mesmo". (E12)

\section{CONCLUSÕES E CONSIDERAÇÕES FINAIS}

Observamos que os profissionais de saúde, no processo de comunicação com os familiares de pacientes internados, perceberam mais os aspectos do que os que facilitam a interação na UTI.

As dificuldades nessa comunicação foram: informações nem sempre compreendidas pelos familiares, a gravidade do paciente, a própria dinâmica da Unidade, o grau de desconhecimento pelo profissional de saúde da evolução clínica do paciente, pois nem sempre têm acesso a todos os seus dados contidos no prontuário no momento da visita hospitalar, além do desconhecimento do modo de ser e perceber da família; dificuldades que são inerentes ao próprio jeito de ser do profissional e espaço físico inadequado da unidade.

A conversa com a família durante o horário de visita é tida como o momento mais difícil e cansativo da UTI, a transferência da responsabilidade da informação, o fornecimento de pouca ou nenhuma informa- ção, as sensações de medo e sentir-se "encurralado" foram sentimentos e comportamentos manifestos pelos profissionais de saúde frente às informações não compreendidas. 0 constrangimento, a insegurança, 0 uso de uma linguagem técnica, o fornecimento de informações superficiais, a alteração do tom de voz e uma abordagem mais formal e prudente, foram citados pelos profissionais de saúde quando a família possui um paciente em estado grave. Outro comportamento manifestado foi evitar a família no momento da visita, quando a dinâmica da Unidade encontrava-se atribulada.

Sensação de desconforto, a decisão de não conversar ou conversar superficialmente com a família foram declarados pelos profissionais quando desconheciam o paciente e a família. No momento da visita, 0 espaço físico inadequado também interfere na atenção do profissional e familia durante a interação.

Em relação aos aspectos que facilitam a comunicação, observamos o interesse do profissional para se aproximar da família, a empatia do profissional pela família, a idade avançada do familiar que estimula a aproximação do profissional, o tempo de experiência do profissional e sua reflexão sobre o autoconhecimento. Os profissionais de saúde que referiram se aproximar da família manifestaram prontidão para responder seus questionamentos. A paciência, uma melhor compreensão do sofrimento do familiar e, até mesmo, a sensibilidade para perceber que a família pode atribuir significados negativos aos gestos do profissional, foram sentimentos e comportamentos que se destacaram e foram descritos pelos profissionais de saúde quando manifestaram empatia.

Neste trabalho fica evidente que os aspectos que dificultam e que facilitam a comunicação com os familiares, na instituição pesquisada, no horário de visita, refletem comportamentos que afastam ou aproximam o profissional de saúde e evidenciam, pela freqüência dos aspectos dificultadores citados, a importância de um suporte e um treinamento para os profissionais conseguirem desenvolver uma comunicação mais efetiva com os familiares e poderem atender a família como um núcleo que também precisa de cuidados.

\section{REFERÊNCIAS}

1. Stefanelli MC. Comunicação com paciente: teoria e ensino. São Paulo (SP): Robe; 1993.

2. Silva MJP. Comunicação tem remédio: a comunicação nas relações interpessoais em saúde. São Paulo (SP): Gente; 1996.

3. Astedt-Kurki P, Paavilainen E, Tammentie T, Paunonen-llmonen M. Interaction between family members and health care providers in acute care setting in Finland. J Fam Nurs 2001; 7(4): 71-90.

4. Hupcey JE. Establishing the nurse-family relationship in the intensive care unit. West Nurs Res 1998; 20(2): 180-94.

5. Collet N. Criança hospitalizada: participação das mães no cuidado [tese] Ribeirão Preto (SP): Escola de Enfermagem de Ribeirão Preto, USP; 2001.

6. Kamada I. Assistência de enfermagem em unidade de terapia intensiva neonatal [tese]. Ribeirão Preto (SP): Escola de Enfermagem de Ribeirão Preto, USP; 2002.
7. Bond AE, Draeger CR, Mandleco B, Donnelly M. Needs of family members of patients with severe traumatic brain injury. Implications for evidence-based practice. Crit Care Nurse 2003; 23(4): 63-72.

8. Söderström IM, Benzein E, Saveman BI. Nurses experiences of interactions with family members in intensive care units. Scand $\mathrm{J}$ Caring Sci 2003; 17(2): 185-92.

9. Silva MJP. Cuidando com qualidade, consciência e confiança: reflexões teóricas. Rev Paul Enferm 2002; 21(1): 5-11.

10. Angelo $M$, Bousso RS. Fundamentos da assistência à família em saúde. [citado em: 10 fev 2004]. Ministério da Saúde. Instituto para o Desenvolvimento da Saúde (IDS). Programa Saúde da Família. Manual de Enfermagem. Brasília (DF); 2001.Disponível em: URL:http://www.ids-saude.orgbr/enfermagem

11. Bardin L. Análise de conteúdo. Lisboa: Edições 70; 1977. 